\title{
PEMANFAATAN MEDIA TI PADA SDN 26 PULAKEK KAB. SOLOK SELATAN UNTUK MENINGKATKAN MUTU DAN INOVASI PEMBELAJARAN
}

\author{
Hariyadi*1, Mahyudin Ritonga $^{2}$, Mimi Sri Irfadila ${ }^{3}$ \\ ${ }^{1}$ Fakultas Teknik, Universitas Muhammadiyah Sumatera Barat \\ ${ }^{2}$ Fakultas Agama Islam, Universitas Muhammadiyah Sumatera Barat \\ ${ }^{3}$ Fakultas KIP, Universitas Muhammadiyah Sumatera Barat \\ email: hariyadi@umsb.ac.id
}

\begin{abstract}
In the current era of globalization, all teachers are required to be able to operate computers. Because one of the professional competencies that must be possessed by a teacher is being able to utilize information and communication technology. At SD N 26 Pulakek, Kab. Solok Selatan utilization of Information Technology media has not been maximally implemented due to limitations in knowledge so that the learning process is still carried out with the help of books or rather manually without the presence of Technology media. The results of the activity can be concluded that 30 Percent Answered Strongly Agree and 70 percent answered agreed and provided benefits to participants in the activity. The benefits obtained from this training are 1. Adding teacher skills in the mastery of information technology. 2. Assist the teacher in making the Learning Module in the form of Ms. Power Point, so as to create an innovative learning module 3. Assist teachers in evaluating learning using information technology
\end{abstract}

Keywords: Media, Learning, Information Technology, Education.

\begin{abstract}
Abstrak
Di era globalisasi seperti saat ini, semua guru dituntut untuk dapat mengoperasikan komputer. Karena salah satu kompetensi professional yang harus dimiliki oleh seorang guru adalah mampu memanfaatkan teknologi informasi dan komunikasi. Pada SD N 26 Pulakek, Kab. Solok Selatan pemanfaatan media Teknologi Informasi belum maksimal dilaksanakan dikarenakan keterbatasan pengetahun sehingga proses pembelajaran masih dilaksanan dengan bantuan buku atau lebih tepatnya manual tanpa adanya media Teknologi. Hasil kegiatan dapat disimpulkan bahwa 30 Persen Menjawab Sangat Setuju dan 70 persen menjawab setuju dan memberikan manfaat terhadap peserta dalam kegiatan tersebut. Manfaat yang diperoleh dari pelatihan ini adalah 1. Menambah keterampilan guru dalam penguasaan teknologi informasi. 2. Membantu guru dalam membuat Modul Pelajaran dalam bentuk Ms. Power Point, sehingga terciptanya modul pembelajaran yang inovatif 3. Membantu guru dalam mengevaluasi pembelajaran dengan menggunakan teknologi informasi
\end{abstract}

Kata Kunci: Media, Pembelajaran, Teknologi Informasi, Pendidikan

\section{PENDAHULUAN}

Perkembangan teknologi informasi dan komunikasi dewasa ini terus mengalami peningkatan, tidak terkecuali dalam bidang pendidikan. Kemajuan teknologi informasi akan menjadi sebuah solusi bagi keterbatasan akses informasi, pekerjaan pada system tradisonal, dan lain sebagainya. Dengan semakin sadarnya masyarakat atas kegunaan teknologi informasi yang tidak lagi bias dipisahkan dalam kehidupan sehari-hari, hal ini dibuktikan dengan semakin meningkat kecenderuan penggunaan simbol "e" yang diartikan sebagai elektronik dan banyak diaplikasikan di hamper semua bidang, sebut saja e-education, egovernment, 
elearning, e-budgeting, e-commerce dan lain sebagainya.

Salah satu standar kompetensi pedagogik guru sekolah dasar berdasarkan permendiknas nomor 16 tahun 2007 tanggal 4 Mei 2007 tentang standar kualifikasi akademik dan kompetensi guru adalah memanfaatkan teknologi informasi dan komunikasi (TIK) Sesuai yang tercantum dalam kurikulum 2013, Teknologi Informasi dan Komunikasi (TIK) diintegrasikan kedalam pembelajaran. Hal ini menjadikan seorang guru diwajibkan untuk menguasai TIK dalam pembelajaran. Peran TIK menjadi sangat penting dalam proses pembelajaran karena dapat meningkatkan efisiensi dan efektivitas pembelajaran sehingga dapat meningkatkan daya tarik dan perhatian peserta didik. Untuk menjadi seorang pendidik yang berkualitas dan professional, guru pada tingkat sekolah dasar dituntut untuk memiliki berbagai macam keterampilan dan keahlian untuk menunjang kegiatan belajar mengajar di sekolah. Di era globalisasi seperti saat ini, semua guru dituntut untuk dapat mengoperasikan komputer. Karena salah satu kompetensi professional yang harus dimiliki oleh seorang guru adalah mampu memanfaatkan teknologi informasi dan komunikasi. Akan tetapi pada kenyataannya tidak semua guru Sekolah Dasar di Indonesia menguasai penggunaan komputer, terutama pada ruang lingkup pedesaan. Akibatnya, siswa siswi Sekolah Dasar tersebut tertinggal dalam penguasaan Ilmu Pengetahuan dan Teknologi ( IPTEK ). Walaupun media pembelajaran berbasis TIK sudah tersedia, namun terdapat perbedaan pemanfaatan TIK dalam meranang, menggunkan dan mengevaluasi kegiatan pembelajaran oleh guru. Hal tersebut dikarenakan kebutuhan TIK setiap guru mata pelajaran yang berbeda. Berdasarkan informasi yang diperoleh dari para guru di SDN 26 Pulakek, Kab. Solok Selatan, masalah yang dihadapi dapat diidentifikasikan sebagai berikut: 1. Bagaimana pemanfaatan teknologi informasi guru dalam proses pembelajaran 2. Para guru belum dapat membuat materi dengan menggunakan Ms. Power Point dengan baik 3. Bagaimana pemanfaatan teknologi informasi guru dalam evaluasi pembelajaran?

\section{METODE PENGABDIAN}

Metode yang digunakan didalam pengabdian ini adalah metode memberikan pengetahuan dan keterampilan dasar di bidang teknologi informasi kepada guru dan tenaga administrasi dalam proses pembelajaran, serta guru dapat membuat materi pembelajaran yang lebih menarik agar siswa bisa bersemagat dalam belajar dengan memanfaatkan Aplikasi Ms. Power Point dengan baik. Diharapkan nantinya dapat menjadi bahan pertimbangan oleh guru untuk mengambil tindakan penggunaan serta peningkatan pembelajaran berbasis TIK dalam rangka implementasi kurikulum 2013.

\section{HASIL DAN PEMBAHASAN}

Kegiatan dilaksanakan pada hari Sabtu 18 Mei 2019 di SD N 26 Pulakek, Kab. Solok Selatan, dihadiri oleh 21 orang guru dan pengawas sekolah. Pelatihan ini menjadi jawaban terhadap persoalan yang dihadapi guru mitra. Modul yang disusun oleh tim memberikan manfaat yang cukup berarti dalam menambah pengetahuan peserta tentang metode pembelajaran inovatif serta cara penerapannya. Pelatihan diawali dengan penyajian materi, dimana peserta diberikan wawasan tentang "Konsep Dasar Metode Pembelajaran Inovatif". Pada session ini ditanamkan pada peserta bahwa guru adalah seorang fasilitator dan pengambil kebijakan dalam pembelajaran. Agar kebijakan yang diambil itu benar dan berarti, maka guru harus bercermin pada proses pembelajaran yang telah dilakukan. Dapat dikatakan, jika proses pembelajaran yang dilakukan tidak baik maka tentu saja kebijakan yang diambil akan bias dan meragukan. Maka untuk memperkaya pengetahuan peserta, 
pada pelatihan ini peserta juga dibeli dengan seluk beluk metode pembelajaran inovatif.

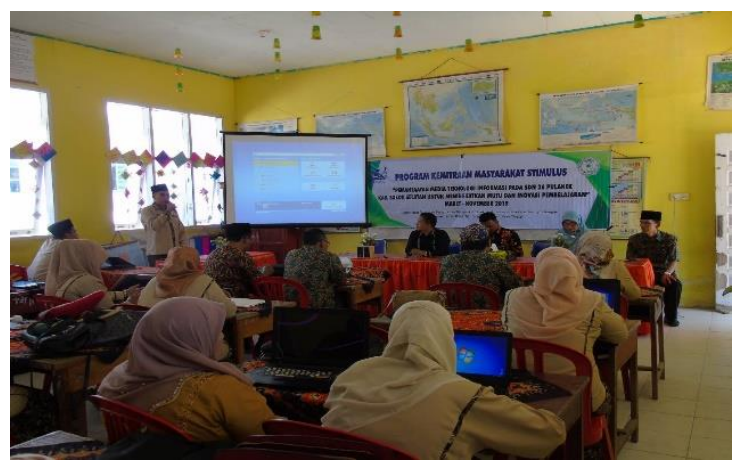

Gambar 1 Penyamapaian Materi

Materi kedua membekali peserta mengenai menggunakan media edomodo untuk pembelajaran e learning bagi guru, harapannya kedepannya guru dapat memberikan tugas kepada siswa melalui aplikasi, sehingga dari kedua materi terbut langsung dapat dipraktekkan oleh guru mitra pada saat materi selesai disampaikan.

Setelah kegiatan berakhir dilakukanlah penilaian angket untuk mendapatkan hasil seberapa pentingnya kegiatan ini dan implementasinya bagi guru-guru di SDN 26 Pulakek, Kab. Solok Selatan agar dapat nantinya dievaluasi

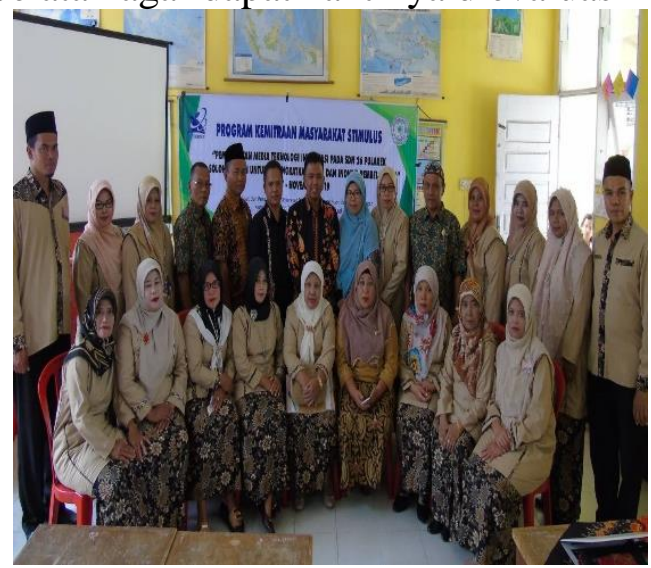

Gambar 2 Foto Bersama guru Mitra

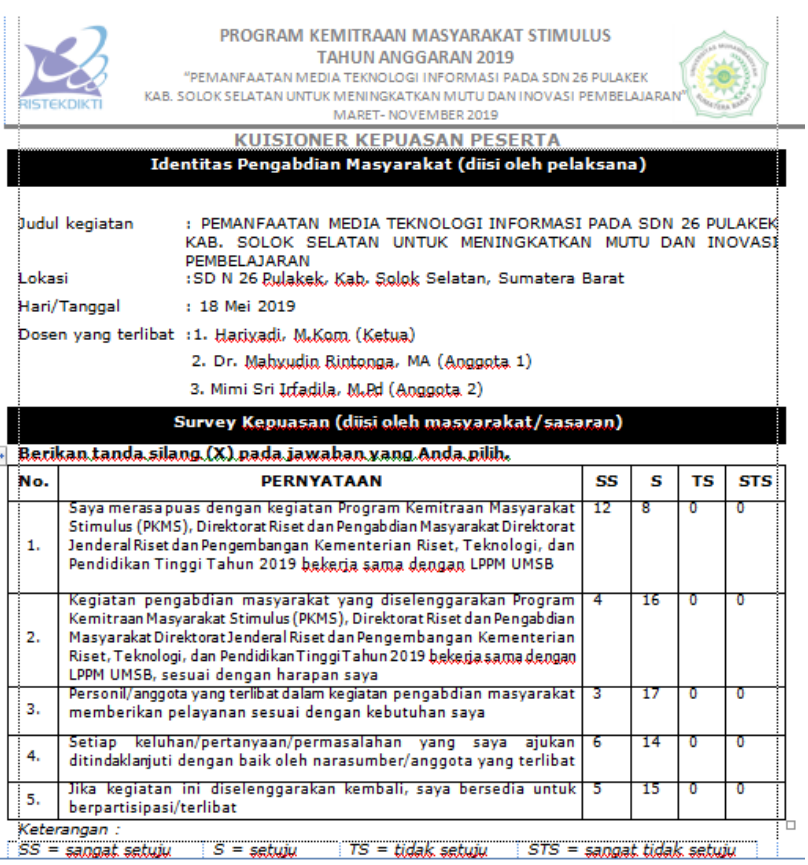

Gambar 3 Hasil Rekap Kuisioner

\section{SIMPULAN}

Dari hasil rekap kuisioner tersebut dapat disimpulkan:

1. 12 orang sangat setuju dan 8 orang setuju dengan kegiatan ini dan merasa puas

2. 4 orang sangat setuju dan 16 orang setuju bahwa kegiatan ini sesuai dengan harapan

3. 3 orang sangat setuju dan 17 orang setuju bahwa pelayanan yang diberikan baik terhadap peserta

4. 6 orang sangat setuju dan 14 orang setuju bahwa setiap pertanyaan ditanggapi dan dijawab dengan baik sesuai dengan harapan

5. 5 orang sangat setuju dan 15 orang setuju agar kegiatan ini diselenggarakan lagi untuk masa yang akan datang.

Dari hasil tersebut dapat disimpulkan bahwa 30 Persen Menjawab Sangat Setuju dan 70 persen menjawab setuju dan memberikan manfaat terhadap peserta dalam kegiatan tersebut.

\section{UCAPAN TERIMAKASIH}

Ucapan terima kasih kepada Direktorat Riset dan Pegabdian Kkeada Masyarakat, Kementrian Riset dan Teknologi yang 
$\overline{I S S N}: 2550-0198$

telah mendanai Pegabdian Masyarakat ini,

Rektor UMSB, Ketua LPPM UMSB dan

Sekolah Mitra SDN 26 Pulakek, Kab.

Solok Selatan

\section{DAFTAR PUSTAKA}

[1]. Anbarini, Ratih. 2013. Terobosan Kemedikbud 2010-2013

Menyiapkan Generasi Emas 2045. Jakarta: Pusat

[2]. Informasi dan Hubungan Masyarakat (PIH) Kementrian Pendidikan dan Kebudayaan Tahun 2013.

[3]. Arikunto, Suharsimi. 2010. Prosedur Penelitian. Jakarta: PT Asdi Mahasatya.

[4]. Depdiknas Dirjen Manajemen Dasar dan Menengah. 2010. Panduan Penyelenggaraan Rintisan Sekolah Bertaraf Internasional (RSBI) untuk Sekolah Menengah Pertama. Jakarta: Dirjen Pembinaan Sekolah Menengah Pertama.

[5]. Peraturan Menteri Pendidikan Nasional Nomor 16 Tahun 2007 tentang Standar Kualifikasi Akademik dan Kompetensi Guru. 